\title{
MERCOSUR: Tendencias de internacionalización y capacidades tecnológicas
}

\author{
Isabel Álvarez, Bruno B. Fischer, José Miguel Natera
}

El Mercado Común del Sur (MERcosur), mundialmente reconocido como una de las entidades de integración regional más avanzadas, atrae crecientemente a empresas multinacionales (EMN) y origina muchas inversiones en el exterior, pese a brechas persistentes en innovación y competitividad. Aquí se analizan las tendencias de internacionalización y tecnología en el MERCOSUR relativas al comercio, las actividades de EMN y los sistemas nacionales de innovación. Mediante el análisis empírico, basado en la estimación de modelos gravitacionales tradicionales, se comprueba el efecto de la inversión extranjera directa (IED) - desde el exterior y en el exterior- en las exportaciones, según su contenido tecnológico. La distribución del ingreso permite aproximar las características institucionales de los países integrantes y, por ello, se analiza su influencia como uno de los aspectos estructurales específicos. Los resultados confirman que las capacidades tecnológicas y de internacionalización - tanto de países inversores como receptores de IED - afectan al comercio dentro del bloque.

PALABRAS CLAVE

CLASIFICACIÓN JEL

AUTORES
MERCOSUR, globalización, competitividad, comercio exterior, inversión extranjera directa, transferencia de tecnología, empresas transnacionales

$\mathrm{F} 1, \mathrm{~F} 4, \mathrm{O} 3$

Isabel Álvarez es profesora de Economía Aplicada del Departamento de Economía Aplicada II e Instituto Complutense de Estudios Internacionales de la Universidad Complutense de Madrid, España. isabel.alvarez@ ccee.ucm.es

Bruno B. Fischer pertenece al Grupo de Investigación en Economía Política de la Innovación (GrineI) de la Universidad Complutense de Madrid, España.bbfischer@pdi.ucm.es

José Miguel Natera pertenece al Grupo de Investigación en Economía Política de la Innovación (GrinEI) de la Universidad Complutense de Madrid, España.jm.natera@pdi.ucm.es 


\section{I}

\section{Introducción}

Los cambios estructurales que se aplicaron en los países del Mercado Común del Sur (MERCOSUR) han contribuido a atraer más empresas multinacionales (EMN) a la región en comparación con el período de industrialización mediante sustitución de importaciones; sin embargo, en estos países aún quedan por resolver los problemas vinculados a la débil especialización e innovación ${ }^{1}$. En este artículo se examinará la relación entre las tendencias de internacionalización y los componentes tecnológicos de las exportaciones, utilizando un marco empírico basado en los modelos gravitacionales que permiten introducir un nuevo enfoque de los procesos de integración en los países en desarrollo ${ }^{2}$.

La producción de las economías del MERCOSUR se caracteriza por la alta proporción de actividades relacionadas con industrias de bajo crecimiento y actividades de escasa innovación, característica que comparten otros países de América Latina. Si bien la participación de la industria manufacturera en las exportaciones creció en estas economías, los productos básicos siguen predominando, lo que puede reducir la competitividad internacional (Cassiolato y Lastres, 1999). Dada esta estructura productiva, los países no logran aprovechar plenamente las ventajas de la especialización tecnológica avanzada, lo que los ayudaría a integrarse mejor a los dinámicos mercados internacionales. Dicha especialización depende, en última instancia, de la estructura industrial de cada país, así como de las características de un complejo conjunto de elementos conocidos como sistemas nacionales de innovación (Narula y Wakelin, 1995).

\footnotetext{
$\square$ Isabel Álvarez agradece el apoyo del Proyecto de Investigación Ref. ECO2010-16609 financiado por el Ministerio de Ciencia e Innovación de España.

Los autores también agradecen los valiosos comentarios y sugerencias formulados por un árbitro anónimo de la Revista CEPAL.

${ }^{1}$ En conjunto, los países de América Latina continúan haciendo inversiones extremadamente limitadas en investigación y desarrollo (I+D) en el ámbito local; véanse Gonçalves, Lemos y De Negri (2008) y Yoguel, Borello y Erbes (2009).

${ }^{2} \mathrm{Si}$ se realizan diferentes búsquedas en la plataforma en línea ISI Web of Knowledge, se observa la escasez de artículos científicos en que se aborda la relación entre la IED y la innovación en el MERCosur (la búsqueda que se realizó con las tres palabras claves solo arrojó un resultado). Este hecho justifica el análisis que se efectúa en este artículo.
}

Si bien la apertura no conduce necesariamente al crecimiento y el desarrollo (Rodrik, 1999; Fagerberg y Srholec, 2008b), ciertas capacidades nacionales se pueden construir o mejorar mediante el comercio, pudiéndose aumentar las ganancias vinculadas a la competitividad con un mayor grado de apertura. Al desarrollar sus actividades productivas y generar valor agregado, las grandes empresas internacionalizadas pueden contribuir a que los países donde tienen sus inversiones ingresen en los segmentos de las cadenas de valor global más sofisticados desde el punto de vista tecnológico y, a su vez, incrementen la capacidad nacional de innovación. Es por ello que estas empresas pueden contribuir no solo a expandir los flujos de inversión entre países, sino también a promover la competitividad de la economía de su país de origen y del país donde tienen inversiones. Este último aspecto se puede apreciar más claramente en los contextos regionales (Rugman y Doh, 2008).

En los últimos años se ha acrecentado la influencia de la IED en los países en desarrollo y también han comenzado a incrementarse las salidas de IED (Chudnovsky, 2001; UNCTAD, 2005 y 2007). En particular, el auge de la IED en los países de América Latina en la década de 1990 fortaleció la posición de las economías del MERCosur en su calidad de inversoras y receptoras de inversión, ya que con mayor frecuencia las empresas multinacionales (EMN) recurrieron a estos países como plataforma para expandir sus actividades en la región. Algunos miembros del bloque supieron aprovechar su potencial como participantes activos en cuanto a la salida de IED. Estas nuevas tendencias justifican el análisis de las corrientes bilaterales entre dichos países a fin de examinar las oportunidades que las EMN pueden estar brindando para la integración tecnológica del bloque, teniendo en cuenta algunas características estructurales de sus países miembros.

En el presente artículo se analiza la relación entre el comercio, la IED y la tecnología en el MERCOSUR, y para ello se asume que la competitividad de los países de América Latina depende de sus capacidades tecnológicas y del acceso al conocimiento (Rosales, 2009). Se utiliza información estadística de varias fuentes internacionales reconocidas para construir modelos gravitacionales que permitan identificar los factores que determinan los flujos comerciales, controlando en 
el análisis por los efectos que generan los patrones de innovación. Para ello se evalúa la influencia de los flujos de IED en el desempeño exportador, desglosado por nivel tecnológico de los productos. Además, se amplía el modelo gravitacional tradicional con el objeto de incluir algunas características específicas de los marcos institucionales y de internacionalización de los países del MERCOSUR, como por ejemplo, la distribución del ingreso medida por el coeficiente de Gini ${ }^{3}$. No obstante, se propone un marco empírico alternativo para estudiar el intercambio en que se considera la internacionalización, el nivel de desarrollo tecnológico y la influencia de las

3 Alonso y Garcimartín (2011) hallaron que el coeficiente de Gini es un indicador robusto de la calidad institucional general. características institucionales nacionales de estos países de América Latina.

El artículo consta de cinco secciones. A la Introducción le sigue, en la segunda sección, una revisión de las principales contribuciones de la literatura sobre el tema. En la tercera sección se describen algunas de las características de la internacionalización de empresas radicadas en países del MERCOSUR y el desempeño innovador de la región, así como las corrientes comerciales y la IED dentro de ella. En la sección IV se incluyen los fundamentos teóricos sobre los que se asienta el presente análisis empírico y la discusión de los resultados. En la última sección se ofrecen las conclusiones extraídas de los resultados obtenidos y se señalan las consecuencias para las políticas y posibles líneas con miras a futuras investigaciones.

\section{II}

\section{Publicaciones sobre el tema}

De acuerdo con la teoría ecléctica, los flujos de IED se pueden explicar atendiendo a la combinación de ventajas de propiedad (Ownership), de localización (Location) y de internalización (Internalization) que las grandes empresas son capaces de aprovechar y que justifican su internacionalización mediante inversiones en el exterior (paradigma OLI) (Dunning, 1977 y 1981). Algunos economistas sostienen que la forma en que la integración regional afecta a la IED depende del atractivo de la localización y el alcance de la liberalización comercial y las políticas de inversión del país (Blomstrom y Kokko, 1997). Según las evidencias disponibles, el efecto de la integración entre los países del MERCOSUR ha sido menor que el de otros procesos de integración regional, como la Unión Europea (Worth, 1997), aunque existe poca información sobre las ventajas de localización para atraer IED en diferentes bloques regionales. En algunos estudios se revela que la repercusión macroeconómica de la IED en los países del MERCosur no es significativa, ya que no genera efectos positivos ni negativos en el crecimiento de la región; no obstante, el efecto microeconómico de la IED parece aumentar sobremanera (Chudnovsky y López, 2007) a medida que las EMN se expanden regionalmente y los países del bloque se vuelven más competitivos que durante el período de industrialización mediante sustitución de importaciones. Los principales fines de la IED - la penetración en el mercado, la mejora de la eficiencia y la adquisición de conocimientosvarían según la etapa de desarrollo económico del país (Dunning, 2006; Narula y Dunning, 2000; Dunning y Narula, 1996). En los países del MERCOSUR, las EMN de los sectores de los servicios y las manufacturas adoptaron una estrategia de búsqueda de mercados, de tal manera que las multinacionales manufactureras aumentaron significativamente las corrientes de exportación, sobre todo hacia los países vecinos (Chudnovsky, 2001). Aun así, existen algunas diferencias entre los países; por ejemplo, algunas empresas del Brasil sostienen estrategias de búsqueda de activos y otras del Uruguay se vuelcan principalmente a la estrategia de búsqueda de recursos haciendo hincapié en las exportaciones, lo que más se asemeja a las estrategias tradicionales de las EMN de la región. La mejora de la eficiencia está creciendo en importancia como motivación: durante el período de industrialización mediante sustitución de importaciones, las filiales de las EMN desarrollaban sus actividades con una fuerte integración nacional, pero a partir de la década de 1990 las estrategias se orientaron a promover la integración del comercio internacional (Chudvnosky, 2001; Chudnovsky y López, 2007).

En la discusión sobre el papel de la innovación en los países en desarrollo se esgrime el interesante argumento de que estos países deberían concentrarse en la adaptación y el uso eficiente de la tecnología existente, 
al menos en las primeras fases del desarrollo, conocidas como etapa de la industrialización (Lall, 1996 y 2000). Sin embargo, es crucial que estos países desarrollen sus propias capacidades tecnológicas para poder adoptar los cambios tecnológicos y las innovaciones implementados en otras partes del mundo (Dahlman, Ross-Larson y Westphal, 1987; Lall, 1992). La decisión de absorber y adaptar tecnologías existentes o crear otras nuevas a partir de mayor investigación y desarrollo (I+D) e innovación es exclusiva de cada nación y depende de su nivel de desarrollo (Gerschenkron, 1962) y grado de modernización. Estas diferencias obedecen fundamentalmente a las posibilidades que brinda la estructura industrial de muchos países en desarrollo, en la que se combinan industrias tradicionales, dotadas de gran densidad de mano de obra, con actividades industriales complejas desde el punto de vista tecnológico (Uchida y Cook, 2005). Si bien la mayor parte de la información proviene de países asiáticos, otros países han sabido crear sus propios nichos tecnológicos (tal es el caso de las aeronaves, la electrónica y las computadoras en el Brasil), combinando medidas gubernamentales con capitales locales y extranjeros.

Una idea bastante generalizada es que la adquisición de conocimientos tecnológicos es un proceso acumulativo, que necesariamente requiere del desarrollo de capacidades de absorción, la participación en redes diversas, la interacción con usuarios y proveedores, y el reconocimiento de otros factores específicos del entorno local (Cantwell, 1989; Lundvall y otros, 2002; Fagerberg y Srholec, 2008a; Álvarez, Marín y Fonfría, 2009; Álvarez y Cantwell, 2011). Por ende, el proceso de modernización puede considerarse como la culminación del proceso de construcción de nuevas capacidades en los países en desarrollo, que consta de dos niveles de acción: por una parte, inversiones en el ámbito nacional en ciencia y tecnología, corrientes de información, infraestructura e instituciones de apoyo; y por otra, medidas a nivel micro de las empresas tendientes a generar nuevas capacidades organizativas y tecnológicas que les permitan aprovechar la nueva información y seleccionar la especialización más ventajosa en relación con otras empresas (Lall, 1997). Debido a que las actividades de innovación y difusión se superponen en un punto, ellas no se desarrollan en etapas consecutivas en todos los casos (López y Lugones, 1997). De hecho, la difusión de tecnología requiere a veces de un cambio técnico permanente (generalmente de carácter gradual) para adaptarse a contextos específicos; no obstante, la creciente internacionalización de las actividades productivas ha permitido a algunos países acelerar el proceso de modernización tecnológica, gracias a las posibilidades inherentes a la cadena de valor global que brinda la transferencia de tecnología —una estrategia que se ha aplicado sistemáticamente en el Asia oriental y América del Norte y Centroamérica. Costa Rica, por ejemplo, se ha especializado en la producción de alta tecnología destinada a la exportación en un corto período de tiempo, pasando de la agricultura en la década de 1980 a la especialización en la alta tecnología focalizada en la electrónica en la década siguiente, y luego a la fabricación de instrumentos médicos y aeronaves en la década de 2000.

A pesar de la diversidad de actividades tecnológicas efectuadas por las EMN en los países receptores (Archibugi y Michie, 1995; Cassiolato y Lastres, 1999; Patel y Pavitt, 2000; Cantwell y Janne, 1999), existe un amplio consenso en que dichas empresas pueden tener un activo papel en la generación y difusión del conocimiento a nivel internacional. Estas empresas pueden ser un canal de acceso a los mercados internacionales a través del comercio y, a su vez, ese acceso puede contribuir a ampliar los sistemas productivos en los que operan las EMN. No obstante, la mayor interacción dentro de la organización respecto del cambio tecnológico y el incremento de la movilidad de las EMN no menoscaba la importancia de fomentar las capacidades locales en los países en desarrollo. De hecho, en un estudio de los efectos de la transferencia tecnológica de EMN estadounidenses, se confirmó la existencia de factores locales que inciden de manera positiva y significativa en el caso de los países desarrollados, pero no en el de los países en desarrollo, siendo el capital humano un elemento determinante que se revela crucial $(\mathrm{Xu}$, 2000). Mortimore y Vergara (2004) demostraron, en su análisis de dos países en América Latina, que la naturaleza de la IED y su efecto dependen de las capacidades tecnológicas, los umbrales de capital humano y las capacidades de los proveedores en el país receptor, y establecieron que se requiere un nivel mínimo de capacidad para beneficiarse de la difusión tecnológica de las EMN. Estos resultados respaldan el papel de los sistemas nacionales de innovación en la atracción de IED.

La participación de las filiales de EMN en el comercio internacional (importaciones y exportaciones) del MERCosur es mayor que la de las empresas nacionales (Chudnovsky y López, 2007). Sin embargo, el contenido tecnológico de las exportaciones de las filiales es menor que el de sus importaciones - especialmente procedentes de sus países de origen - y la mayor parte de las exportaciones se dirigen a los países en desarrollo, 
sobre todo en América Latina. Los patrones de especialización de las filiales en el MERCosUR presentan dos características notables: exportan al bloque y el resto de América Latina bienes tecnológicamente sofisticados y con alto valor agregado, mientras que importan bienes de capital, insumos y componentes de los países desarrollados (Chudnovsky, 2001). Por otra parte, como demuestran los resultados de algunos estudios de caso, en la secuencia de internacionalización seguida por las EMN de los países latinoamericanos — las llamadas multilatinas-, se describen algunas estrategias de sus filiales en que se ha priorizado la instalación de capacidades productivas por sobre las actividades de comercialización en el extranjero, con el propósito de conseguir un mayor aprovechamiento de las ventajas de localización (Cuervo-Cazurra, 2007).

En décadas recientes, los países del mercosur han introducido políticas para atraer a la inversión extranjera y mejorar la calidad y productividad de las empresas locales a fin de aumentar la competitividad de sus economías, habiéndose asistido también al impulso de las multilatinas. Sin embargo, el papel cada vez más creciente de los flujos de tecnología y la actividad de las EMN en el proceso de integración regional no se ha explorado mucho en la literatura, lo que brinda una nueva oportunidad de investigación.

\section{III}

\section{Breve descripción de los datos}

En lo concerniente a los flujos de IED captados por las economías del MERCosur, estos han sido positivos en todos los países del bloque en décadas recientes (véase el gráfico 1). Sin embargo, en el período comprendido entre 1980 y 2008, la Argentina y el Brasil atrajeron más IED en términos relativos que el Paraguay y el Uruguay, como demuestran las cifras correspondientes al volumen de IED recibida como porcentaje del producto interno bruto (PIB). El volumen de IED del exterior comenzó a decaer a principios de la década de 1990 en todos los países, excepto en la Argentina, y disminuyó abruptamente a principios del decenio de 2000 en todos ellos, incluida la Argentina, debido no solo al ciclo económico mundial, sino también a las crisis políticas y económicas internas que afectaron a estos países. En el año 2000, el Uruguay superó al Brasil y la Argentina y tomó el primer lugar en este indicador en el MERCOSUR (UNCTAD, 2005 y 2007). En general, la IED ha crecido como proporción del PIB en las últimas décadas, aunque se estabilizó y disminuyó levemente en la década de 2000, salvo en el Uruguay.

Con respecto al volumen de IED en el exterior como proporción del PIB, las empresas del Brasil y la Argentina son las que muestran la mayor capacidad de invertir en el extranjero, ya que cuentan con las ventajas comparativas inherentes a su tamaño para estimular el proceso de capitalización necesario para establecer EMN. Los valores de este indicador correspondientes a los países más pequeños (Paraguay y Uruguay) son bastante menores en comparación con los del Brasil y la Argentina (véase el gráfico 1). En el período en consideración, las EMN de los dos países más grandes han tenido un desempeño muy positivo. En la Argentina hubo un gran salto en el volumen de IED en el exterior en 2002, y durante varios años se registraron niveles más altos que en el Brasil. Las fugas de capitales en la Argentina variaron sustancialmente durante todo el período, aunque la tendencia general fue positiva. En el Brasil se observaron fluctuaciones más moderadas. De todos modos, las diferencias entre los países son menos notorias que las correspondientes a la IED del exterior. El volumen de la IED brasileña en el exterior ha crecido de manera estable desde fines de la década de 1990, mientras que el volumen de la IED argentina también seguía el mismo camino hasta que cayó bruscamente en 2002. Los datos correspondientes al Paraguay y al Uruguay muestran que la IED en el exterior de estos dos países ha estado bastante estancada.

En el gráfico 2 se muestra el gasto en I+D como porcentaje del PIB. Este indicador puede arrojar algo de luz sobre la innovación en los países del MERCOSUR y es una variable sustitutiva de la inversión en el desarrollo de las capacidades tecnológicas, que puede definirse como "la habilidad de buscar, generar y utilizar el conocimiento comercialmente" (Fagerberg y Shrolec, 2009). La capacidad de cada país de ser más productivo en la economía de aprendizaje depende de la magnitud de sus esfuerzos por alcanzar los niveles más altos de conocimiento que conducen a mayores beneficios económicos (Lundvall y Johnson, 1994). Si bien el gasto en I+D proporciona solo una visión parcial de las 
MERCOSUR: volumen de IED del exterior y en el exterior, por país, 1990-2008

(En porcentajes del PIB)

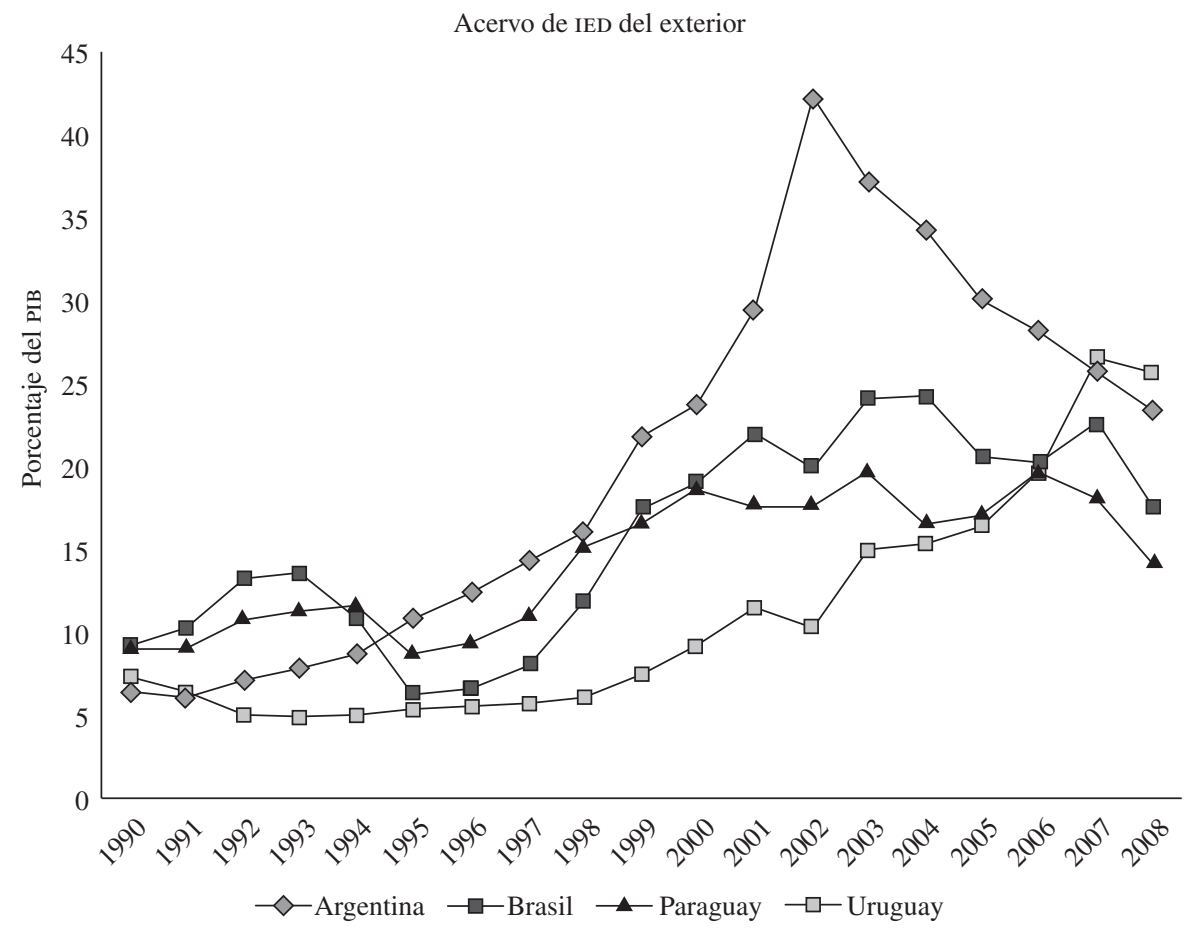

Acervo de IED en el exterior

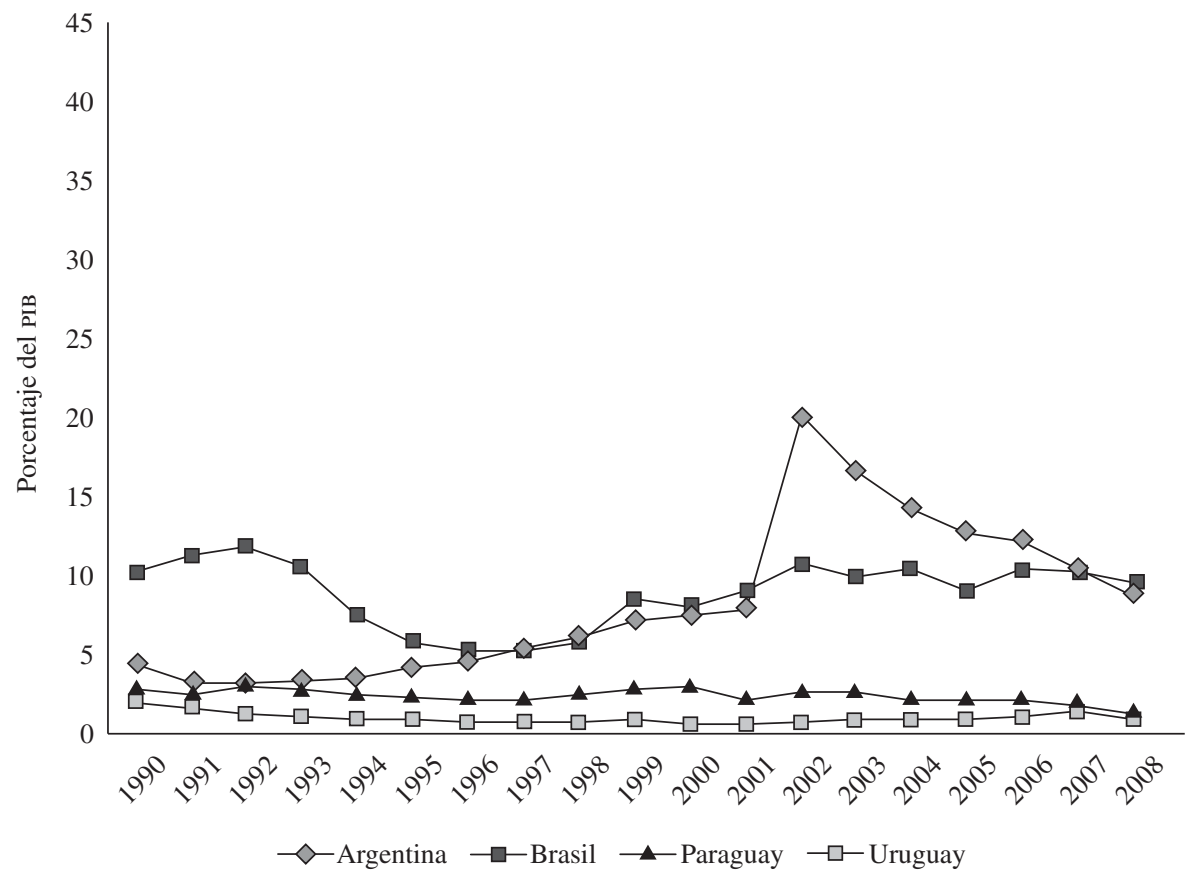

Fuente: Conferencia de las Naciones Unidas sobre Comercio y Desarrollo (UNCTAD), UnCTADSTAT [en línea] http://unctadstat.unctad.org/ 
medidas que están tomando los países para desarrollar sus capacidades tecnológicas, revela que el Brasil está a la vanguardia en la creación de nuevas oportunidades en la región, tanto en términos absolutos (debido al tamaño de la economía brasileña) como relativos (véase el gráfico 2). El gasto en I+D como porcentaje del PIB en la región se ha mantenido relativamente inalterado en los últimos 15 años, en que el Brasil ha estado a la cabeza, seguido de la Argentina y el Uruguay, mientras que el Paraguay está muy rezagado.
En los cuadros 1 y 2 se muestra la distribución de las EMN más grandes de los países del MERCOSUR y de países fuera de la región ${ }^{4}$. Como se aprecia en el cuadro 1 ,

\footnotetext{
${ }^{4}$ Los datos se obtuvieron de los perfiles nacionales de inversión de la Conferencia de las Naciones Unidas sobre Comercio y Desarrollo (UNCTAD), en que se detallan las empresas multinacionales extranjeras más grandes en el país receptor y las filiales extranjeras más grandes de las EMN con sede en el país de origen.
}

GRÁFICO 2

Gasto en I+D como porcentaje del PIB

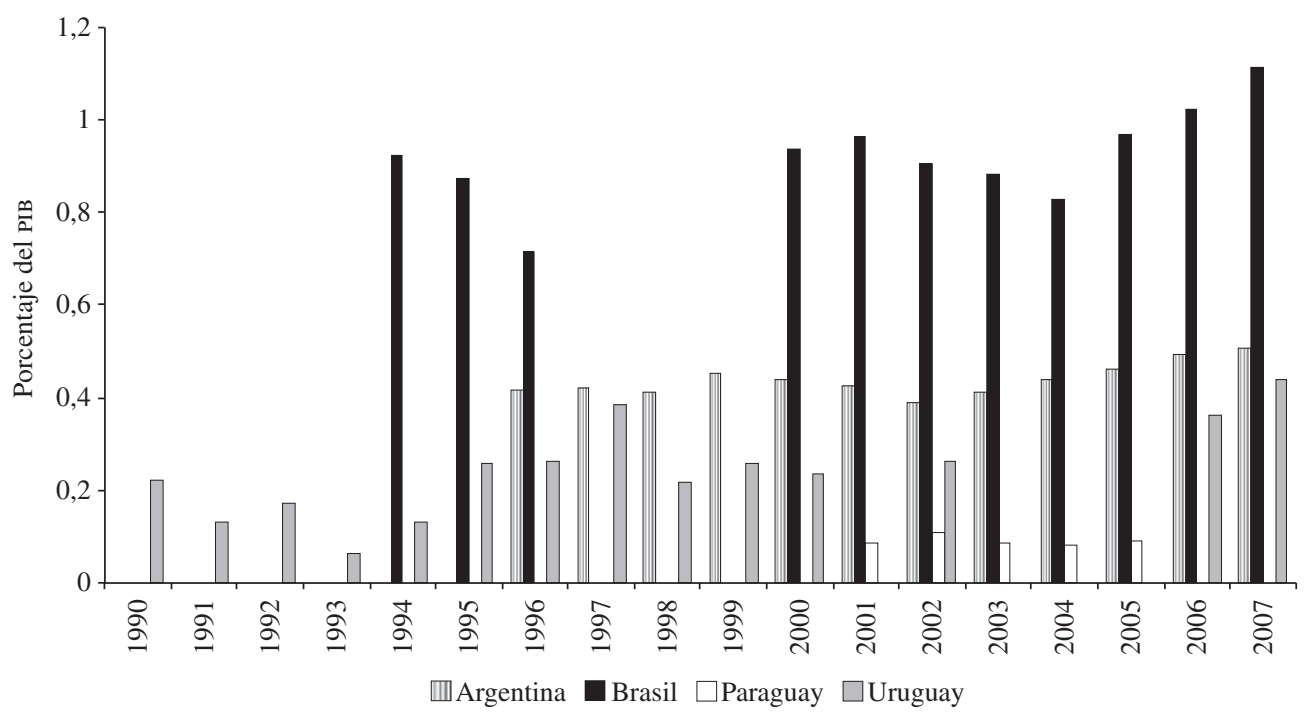

Fuente: Red Iberoamericana de Indicadores de Ciencia y Tecnología (RICYT).

CUADRO 1

Ubicación de las mayores filiales extranjeras de EMN con sede en países del MERcosUR (En porcentajes)

\begin{tabular}{lccccc}
\hline & & & & \\
País receptor & Argentina & Brasil & Paraguay & Uruguay & Otros \\
País de origen & & & & & \\
Brasil & 21,2 & 34,3 & 0,0 & 34,3 & 31,4 \\
Paraguay & - & - & 0,0 & 3,0 & 75,8 \\
Uruguay & 58,1 & 29,0 & 3,2 & - & - \\
\hline
\end{tabular}

Fuente: perfiles nacionales de inversión extranjera directa (IED) de la Conferencia de las Naciones Unidas sobre Comercio y Desarrollo (UNCTAD). EMN: empresas multinacionales. 
casi el 70\% de las mayores EMN argentinas tienen filiales en el Brasil o el Uruguay, lo que revela cuán atractivo es el bloque regional para las empresas de dicho país. Del mismo modo, las empresas uruguayas tienden a enfocarse en otros países de la región: más del $90 \%$ de las mayores EMN uruguayas se establecen en la Argentina, el Brasil o el Paraguay. En cambio, el patrón de las multinacionales brasileñas es bastante distinto, dado que los países del MERCOSUR no están dentro de sus objetivos principales de la IED (a excepción de la Argentina, que acoge al 21,2\% de las EMN más importantes del Brasil). No hubo datos disponibles con respecto al Paraguay.

En el cuadro 2 se observa que la proporción de países del MERCOSUR que acogen a las mayores EMN extranjeras es bastante reducida. De hecho, ninguna de las empresas más importantes de capital extranjero que operan en el Brasil y la Argentina proviene de un país del bloque. Si bien las empresas brasileñas y sobre todo las argentinas tienen cierta presencia como grandes empresas de capital extranjero que operan en el Paraguay y el Uruguay, las que predominan son las EMN de otros países, que alcanzan aproximadamente al $75 \%$ en ambos casos. Por lo tanto, en estos dos cuadros se muestra que el MERCOSUR es un destino importante para la IED de las EMN dentro del bloque (IED en el exterior de países miembros), pero que la IED del exterior está mayormente dominada por empresas de países de fuera de la región.

Por último, la información sobre los flujos comerciales entre los países del MERCOSUR proporciona una visión más detallada de las tendencias de internacionalización. En el gráfico 3 se presentan los perfiles de exportación de los países del bloque (solo se consideran las corrientes comerciales dentro del MERCOSUR) de acuerdo con la clasificación según contenido tecnológico de las exportaciones sugerida por Hatzichronoglou (1997) ${ }^{5}$. La gran

${ }^{5}$ No hay datos disponibles de 1994 sobre el Brasil y de 1992 respecto del Uruguay.
CUADRO 2

Presencia de los países del MERcosur como receptores de las filiales más grandes de EMN extranjeras

(En porcentajes)

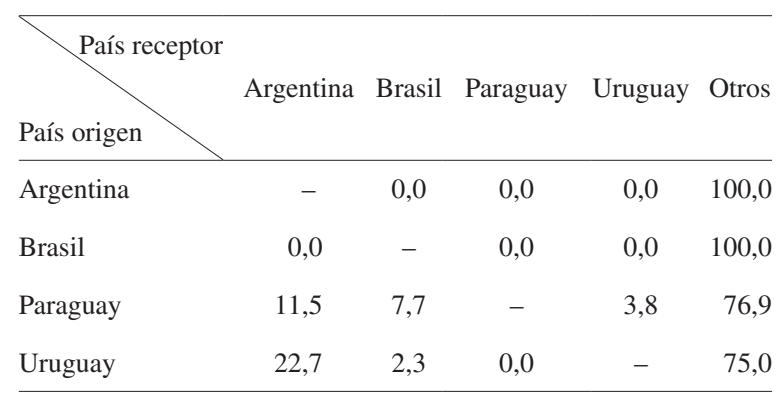

Fuente: perfiles nacionales de inversión extranjera directa (IED) de la Conferencia de las Naciones Unidas sobre Comercio y Desarrollo (UNCTAD).

EMN: empresas multinacionales.

mayoría de las exportaciones del Paraguay son de baja tecnología, y los otros tipos de productos representan una proporción insignificante de su estructura de exportación. En general, el desglose de las exportaciones de la Argentina, el Brasil y el Uruguay es más avanzado desde el punto de vista tecnológico. La proporción de productos de baja tecnología ha disminuido en la Argentina y el Brasil, aunque sigue siendo considerable en la Argentina y es alta en el Uruguay. Cabe destacar que la categoría de tecnología media-alta se ha expandido en los últimos años del período en consideración. La proporción de productos de alta tecnología exportados por el Brasil y la Argentina a sus socios del MERCOSUR es muy pequeña y no se ha acrecentado con el tiempo, lo que indica una debilidad importante que puede tener consecuencias interesantes para el comercio dentro del bloque, y fomentar a la larga una mayor especialización en las actividades de valor agregado más elevado —en particular en el Brasil y la Argentina— en relación con los mercados vecinos. 
GRÁFICO 3

Perfiles nacionales de exportación según la clasificación tecnológica de los productos, 1992-2008

(En porcentajes)

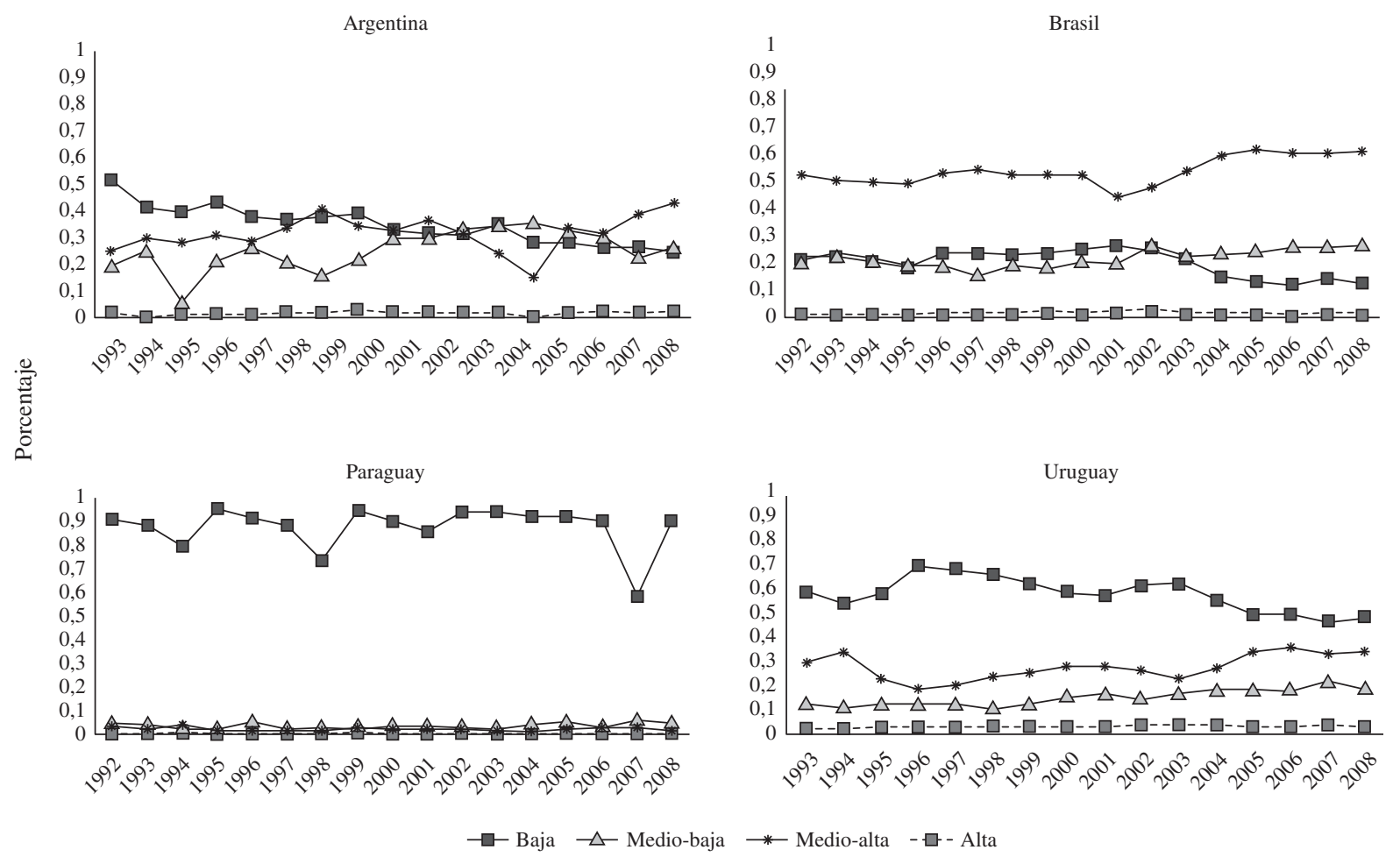

Fuente: sobre la base de los datos del Banco Interamericano de Desarrollo (BID), DATAINTAL: Sistema de estadísticas de comercio de América, Washington, D.C., 2010.

\section{IV}

\section{Modelo y resultados empíricos}

La estimación de modelos de comercio internacional tiene una larga tradición en economía y el uso de ecuaciones gravitacionales en relación con el comercio bilateral, en particular, ha dominado la investigación empírica acerca del comercio internacional. De esta manera, el volumen de comercio entre dos países es proporcional al tamaño de sus economías, y el factor de proporcionalidad depende de las medidas de resistencia al comercio entre ellos (Anderson, 1979; Helpman y Krugman, 1985; Helpman, 1984; Feenstra, 2002; Anderson y Van Wincoop, 2003). Este enfoque ha sido complementado con fundamentos teóricos y mejores técnicas de estimación, dado que en la mayor parte de los estudios se ha estimado la ecuación gravitacional mediante muestras de países que solo tienen corrientes comerciales positivas entre ellos, dejando de lado a los países que no comercian entre sí. La especificación estándar de la ecuación gravitacional impone una simetría que no concuerda con los datos, y esto conduce a estimaciones sesgadas. Este problema se corrigió en Helpman, Melitz y Rubinstein (2008), donde mediante un modelo simple de comercio internacional con empresas heterogéneas se predijo un nivel de comercio positivo, así como nulo, en distintos pares de países, permitiendo que varíe el número de empresas exportadoras en los países de destino ${ }^{6}$.

\footnotetext{
${ }^{6}$ Esto implica un procedimiento de estimación de dos etapas, en que se utiliza una ecuación para seleccionar los socios comerciales en la primera etapa y una ecuación de corrientes comerciales en la segunda.
} 
Al utilizar el modelo gravitacional en el análisis del comercio bilateral es preciso considerar algunas cuestiones metodológicas. Un aspecto crucial es la especificación econométrica del modelo gravitacional, así como la validez y confiabilidad de la estimación (Greenaway y Milner, 2002; Gil y otros, 2005). En muchas ocasiones se han cuestionado las estimaciones de ecuaciones gravitacionales en que se emplean muestras representativas o datos combinados sobre el comercio total porque, entre otros motivos, las estimaciones por mínimos cuadrados ordinarios (MCO) no reflejan la heterogeneidad inherente a las corrientes comerciales bilaterales. Una solución adecuada para este problema es el empleo de datos de panel, puesto que permiten tener en cuenta las características individuales de cada par de países. No obstante, en este caso no ha sido posible aplicar esta solución dada la limitada disponibilidad de datos en general y la falta de datos de panel para el análisis empírico del comercio interno dentro del MERCOSUR, ya que las corrientes bilaterales en el período determinado ofrecen pocas observaciones. A fin de solucionar esta limitación, se ha aplicado un modelo de regresión conjunta para el período de 1992 a 20087 , lo que justifica el uso de estimaciones simples por MCO.

El objetivo de este análisis empírico es estudiar el comercio entre los países del MERCOSUR y cómo los procesos de internacionalización de estos pueden estar condicionados tanto por los patrones de IED como por los contextos institucionales. Para realizarlo, se ha utilizado el marco provisto por los modelos gravitacionales, ampliándose en las siguientes dos direcciones: por una parte, se asume que los procesos de transferencia tecnológica contribuyen a definir el sistema de innovación de un país; ello justifica considerar tanto la capacidad de absorción de tecnología procedente del exterior (a través de la IED extranjera) como el desarrollo de capacidades propias (que se expresa en la IED emitida hacia el extranjero), y que en la estimación del modelo se controle, además, el efecto que tiene el comercio de conocimiento desincorporado (a través de los ingresos por concepto de regalías). Por otra parte, también se incorporan en el modelo algunos indicadores que reflejan las características del marco institucional de los países del bloque.

\footnotetext{
7 Anderson (1979) sugiere, en su influyente artículo "A theoretical foundation for the gravity equation", que los modelos con datos combinados son una forma funcional de las ecuaciones gravitacionales operativas. Se utiliza el método de estimación por mínimos cuadrados ordinarios (MCO).
}

Una de las contribuciones del presente estudio a la literatura sobre este tema es una versión modificada del modelo gravitacional que toma en cuenta los aspectos estructurales de las economías que participan en el comercio. La distribución del ingreso, que puede medirse en la mayor parte de los países latinoamericanos, se utiliza como un indicador sustitutivo de la organización institucional de los países (Alonso y Garcimartín, 2011). Si bien los fundamentos teóricos precisos para la inclusión de estos factores determinantes en los modelos de comercio o IED todavía no se han establecido, cabe esperar que una mayor especialización en actividades de alta tecnología se relacione positivamente con una economía más desigual (Freeman, 2011). De hecho, se espera que los países con niveles más altos de internacionalización tecnológica tengan índices de Gini más altos y, por lo tanto, se obtenga un signo positivo en el coeficiente estimado de esta variable. Por otra parte, para analizar los distintos niveles de tecnología en los bienes comercializados entre los países del MERCosur se utilizó la clasificación definida por la Organización de Cooperación y Desarrollo Económicos (OCDE), en la que se distingue contenido tecnológico bajo, medio-bajo, medio-alto y alto. Dado que esta clasificación se elaboró para los países desarrollados, en este estudio se combinan el contenido tecnológico medio-alto y el alto en una sola categoría.

En consecuencia, la ecuación (1) es la estimación del modelo básico de comercio, mientras que la ecuación (2) incluye la variable institucional descrita anteriormente (véase la descripción de las variables en el cuadro 3):

$$
\begin{gathered}
\ln \operatorname{TR}_{i j t}=\ln G D P P C_{j t}+\ln P O P_{j t}+ \\
\ln D I S T_{i j}+\ln F D I_{i t}+\ln R O Y A L T Y R C P T_{i t}+\varepsilon_{i j t} \\
\operatorname{lnTRD}_{i j t}=\ln G D P P C_{j t}+\ln G I N I_{j t}+\ln P O P_{j t}+ \\
\operatorname{lnDIST}_{i j}+\ln F D I_{i t}+\ln R O Y A L T Y R C P T_{i t}+\varepsilon_{i j t}
\end{gathered}
$$

donde:

$T R D_{i j t}$ : corriente comercial del país "i" (exportador) al país “ "j" (importador) en el período " $\mathrm{t}$ ".

$G D P P C_{j t}$ : PIB per cápita del país importador “j” en el período " $\mathrm{t}$ ".

$P O P_{j t}$ : población del país importador “j”" en el período " $\mathrm{t}$ ”. $D I S T_{i j}$ : distancia medida en kilómetros entre las capitales del país "i” y el país “j”.

$F D I_{i t}$ : IED del exterior correspondiente al país exportador " $\mathrm{i}$ " en el período " $\mathrm{t}$ " utilizada para verificar la repercusión de las EMN extranjeras en la capacidad exportadora del país; e IED en el exterior en el período "t" como representación del nivel de internacionalización del país. Esta variable toma en cuenta los flujos totales de 
Códigos, descripción y fuentes de variables operativas

\begin{tabular}{|c|c|c|}
\hline Variable & Descripción & Fuente \\
\hline$T R D$ & $\begin{array}{l}\text { Corrientes comerciales bilaterales, } 1992 \text { a } 2008 \text {, clasificadas en } \\
\text { tres grupos por contenido tecnológico, según la definición de } \\
\text { Hatzichronoglou (1997): bajo, medio-bajo y medio-alto y alto }\end{array}$ & DATAINTAL, Banco Interamericano de Desarrollo \\
\hline GDPPC & Producto interno bruto per cápita, 1992-2008 & $\begin{array}{l}\text { Indicadores del Desarrollo Mundial, Banco } \\
\text { Mundial }\end{array}$ \\
\hline$P O P$ & Población, 1992-2008 & $\begin{array}{l}\text { Indicadores del Desarrollo Mundial, Banco } \\
\text { Mundial }\end{array}$ \\
\hline DIST & $\begin{array}{l}\text { Distancia entre las capitales de los países (para el Brasil se } \\
\text { utilizó el centro económico, São Paulo, en lugar de Brasilia) }\end{array}$ & - \\
\hline FDIIN & IED total del exterior, 1992-2008 & UNCTADStat \\
\hline FDIOUT & IED total en el exterior, 1992-2008 & UNCTADStat \\
\hline GINI & Coeficiente de Gini, 1992-2008 & CANA Database \\
\hline
\end{tabular}

Fuente: elaborado por los autores.

IED y no refleja solamente la IED interna en los países del MERCOSUR.

ROYALTYRCPT $T_{i}$ : entradas por concepto de regalías del país exportador "i" en el período " $\mathrm{t}$ ".

GINI $_{j t}$ : coeficiente de Gini del país “j” (importador) en el período " $\mathrm{t}$ ".

$\varepsilon_{i j t}$ : término de error de las corrientes comerciales entre el país "i” y el país “j” en el período "t".

Se espera que el PIB per cápita y el tamaño de la población del país importador tengan un efecto positivo en el volumen de comercio, y que los mercados más importantes atraigan más flujos comerciales. Se espera, además, que la mayor distancia entre las capitales tenga una repercusión negativa, bajo el supuesto de que es más probable que los mercados que están cerca unos de otros comercien entre sí. Si bien habitualmente el PIB es una de las variables aplicadas en los modelos gravitacionales (véanse, por ejemplo, Brenton, Di Mauro y Lücke, 1999; Bloningen y otros, 2007; Feenstra, Markusen y Rose, 2001; Anderson y Van Wincoop, 2003; Frankel, Stein y Wei, 1995; Feenstra, 2002; Anderson, 1979), en el presente análisis se utiliza el PIB per cápita porque proporciona una medida del poder adquisitivo que refleja los niveles de desarrollo dentro de los mercados del MERCOSUR. Al incluir el PIB per cápita y el tamaño de la población, se puede aislar el efecto del tamaño del mercado en una descomposición básica del PIB.

Cabe igualmente resaltar algunas características sociales y económicas relevantes que pueden ayudar a caracterizar a los países en consideración. En primer lugar, el Brasil es el líder indiscutible en términos de PIB y tamaño de población, pero ocupa el tercer puesto entre los países del MERCOSUR en relación con el PIB per cápita. En segundo término, con respecto a la distribución del ingreso, el Brasil y el Paraguay tienen los coeficientes de Gini más altos en el bloque. Estas características representan un claro desafío para la aplicación de los modelos gravitacionales, dado que los resultados pueden estar condicionados por las expectativas derivadas de las características institucionales del Brasil —el país miembro más influyente. Por lo tanto, resulta pertinente incluir las características institucionales que fomentan el desarrollo para evitar resultados sesgados, en especial teniendo en cuenta "la complejidad institucional de los países latinoamericanos".

Los resultados de las estimaciones calculadas utilizando las ecuaciones (1) y (2) justifican el interés de este estudio en los sistemas nacionales de innovación. Las estimaciones se efectuaron tanto sobre datos agregados de comercio (corrientes comerciales totales) como respecto de los datos desagregados por el contenido tecnológico de las exportaciones (productos de baja, media-baja y media-alta y alta tecnología). Asimismo, se replicaron estimaciones diferentes para las corrientes bilaterales con la región latinoamericana en conjunto, así como con los Estados Unidos de América y Europa, incluido el MERCOSUR como variable de control. Las estimaciones confirman que este acuerdo comercial regional tiene efecto en los flujos comerciales y de IED. 
En el cuadro 4 se indican los resultados de un modelo gravitacional típico en que se examina el efecto que tiene el capital extranjero en la capacidad de exportación de un país receptor mediante el análisis de la IED del exterior y las variables gravitacionales habituales correspondientes a los mercados de importación, sin considerar el monto de las regalías recibidas por el país exportador. Como era de esperar, la variable DIST (medida en kilómetros) tiene una repercusión uniformemente negativa en el comercio $^{8}$. Los coeficientes estimados, que corresponden al tamaño de la población (la variable POP), son todos significativos y positivos, donde cabe considerar que la población brasileña es notablemente mayor que la de los demás países sudamericanos. La variable del PIB per cápita solo es estadísticamente significativa en relación con el comercio de productos de media-baja y media-alta y alta tecnología, y el signo negativo del

${ }^{8}$ Pese a que se puede esperar un coeficiente menor con respecto al de los productos con mayor contenido tecnológico. coeficiente estimado — contrariamente a lo que se espera normalmente de los modelos gravitacionales - viene a revelar los patrones de consumo menos sofisticados de estos países. Ello puede deberse a la notable influencia del Brasil en el bloque, cuyo PIB per cápita es más bajo que el del Uruguay y la Argentina a pesar de ser el líder del mercado en la región. En el período en consideración, el indicador ROYALTYRCPT no es significativo con respecto a los intercambios comerciales de más alto contenido tecnológico. Entretanto, el efecto de la IED del exterior en el comercio entre países del MERCOSUR es significativo y positivo, y su influencia (coeficientes) aumenta en consonancia con el contenido tecnológico de las exportaciones. De ello se desprende que el capital extranjero y el comercio intraempresa resultante de la integración de cadenas de valor global puede estimular la capacidad exportadora de los países del MERCOSUR, lo que promovería la generación de capacidades y un comercio con mayor valor agregado dentro del bloque. Sin embargo, una implicancia a tener en cuenta que se desprendería de lo anterior, es que la capacidad de

CUADRO 4

Modelo gravitacional típico: análisis de la IED del exterior según el contenido tecnológico del comercio

\begin{tabular}{|c|c|c|c|c|}
\hline & Todas las corrientes comerciales & Baja tecnología & Media-baja tecnología & Media-alta y alta tecnología \\
\hline $\ln G D P P C_{j t}$ & $\begin{array}{c}-0,056 \\
{[0,105]} \\
(0-, 54)\end{array}$ & $\begin{array}{l}0,024 \\
{[0,102]} \\
(0,24)\end{array}$ & $\begin{array}{l}-0,457 * * * \\
{[0,191]} \\
(-2,40)\end{array}$ & $\begin{array}{l}-0,501 * * * \\
{[0,213]} \\
(-2,35)\end{array}$ \\
\hline $\ln P O P_{j t}$ & $\begin{array}{c}0,847 * * * \\
{[0,029]} \\
(29,23)\end{array}$ & $\begin{array}{c}0,709 * * * \\
{[0,028]} \\
(25,33)\end{array}$ & $\begin{array}{l}1,104 * * * \\
{[0,052]} \\
(21,12)\end{array}$ & $\begin{array}{c}1,038 * * * \\
{[0,058]} \\
(17,77)\end{array}$ \\
\hline $\ln D I S T_{i j}$ & $\begin{array}{l}-0,324 * * * \\
{[0,056]} \\
(-5,79)\end{array}$ & $\begin{array}{c}-0,201 * * * \\
{[0,054]} \\
(-3,71)\end{array}$ & $\begin{array}{l}-0,624 * * * \\
{[0,101]} \\
(-6,17)\end{array}$ & $\begin{array}{l}-0,577 * * * \\
{[0,113]} \\
(-5,11)\end{array}$ \\
\hline $\operatorname{lnFDIIn}_{i t}$ & $\begin{array}{c}0,700 * * * \\
{[0,019]} \\
(35,83)\end{array}$ & $\begin{array}{c}0,541 \text { *** } \\
{[0,018]} \\
(28,68)\end{array}$ & $\begin{array}{l}0,865 \text { *** } \\
{[0,035]} \\
(24,54)\end{array}$ & $\begin{array}{c}1,086 * * * \\
{[0,039]} \\
(27,59)\end{array}$ \\
\hline $\operatorname{lnROYALTYRCPT_{it}}$ & $\begin{array}{l}0,082 * * * \\
{[0,015]} \\
(5,31)\end{array}$ & $\begin{array}{l}0,037 \text { *** } \\
{[0,015]} \\
(2,47)\end{array}$ & $\begin{array}{l}0,146^{* * * *} \\
{[0,028]} \\
(5,24)\end{array}$ & $\begin{array}{l}0,009 \\
{[0,031]} \\
(0,30)\end{array}$ \\
\hline Constante & $\begin{array}{l}-6,055^{* * *} \\
{[0,969]} \\
(-6,24)\end{array}$ & $\begin{array}{c}-4,04 * * * \\
{[0,937]} \\
(-4,31)\end{array}$ & $\begin{array}{l}-8,889 * * * \\
{[1,749]} \\
(-5,08)\end{array}$ & $\begin{array}{l}-7,429 * * * \\
{[1,954]} \\
(-3,80)\end{array}$ \\
\hline$R^{2}$ ajustado & 0,915 & 0,882 & 0,837 & 0,838 \\
\hline
\end{tabular}

Fuente: elaborado por los autores.

Nota: las fuentes de las variables individuales están indicadas en el cuadro 3. Los errores estándar se indican entre corchetes. Las cifras entre paréntesis son los valores de $\mathrm{t}$.

*** Nivel de significancia del $1 \%$. 
exportación de los países podría volverse cada vez más dependiente de las EMN de terceros países.

Enseguida estimamos un modelo similar, esta vez utilizando la IED en el exterior para evaluar la influencia de la capacidad de internacionalización de los países del MERCOSUR en sus estructuras comerciales dentro del bloque (véase el cuadro 5). Nuevamente el desempeño del PIB per cápita como variable gravitacional es deficiente, mientras que los coeficientes de tamaño de población se mantienen robustos y significativos, de modo similar al resultado del conjunto de modelos utilizados para evaluar la IED del exterior. Los resultados de la variable distancia $\left(D I S T_{i j}\right)$ también son similares a los obtenidos en la estimación anterior. En cambio, el coeficiente estimado para la variable referida a las regalías recibidas ( $\left.R O Y A L T Y R C P T_{i t}\right)$ es más irregular cuando se trata de la IED en el exterior. Las fortalezas de internacionalización de los países del MERCOSUR, medidas en relación con la IED en el exterior, varían según el contenido tecnológico de las exportaciones, aunque en menor medida que con respecto a la IED del exterior. Estos resultados respaldan la evidencia presentada en la literatura relacionada: la generación de capacidades internas fomenta la internacionalización tanto de la inversión como del comercio.

En la última etapa del presente estudio, se utiliza un modelo gravitacional adaptado en el que se reflejan ciertas características institucionales. Se ha incluido el coeficiente de Gini como variable de control relacionada con el marco institucional - lo que constituye un hecho sin precedentes en investigaciones previas sobre este tema-, con el objeto de brindar una evaluación más precisa del bloque que se está analizando (véanse los cuadros 6 y 7). Según las estimaciones, la variable población $\left(P O P_{j t}\right)$ es una vez más uniformemente positiva y representa una distinción especial para el caso del comercio de media-alta tecnología dentro del MERCOSUR, lo que podría indicar el perfil importador de la principal economía en este contexto. La variable distancia $\left(D I S T_{i j}\right)$ es nuevamente negativa (véase el cuadro 6). El papel de la IED del exterior es similar al observado en las estimaciones anteriores y, por lo tanto, se supone que tendrá las mismas consecuencias que las mencionadas con antelación. Aunque los resultados

CUADRO 5

Modelo gravitacional típico: análisis de la IED en el exterior según el contenido tecnológico del comercio

\begin{tabular}{|c|c|c|c|c|}
\hline & Todas las corrientes comerciales & Baja tecnología & Media-baja tecnología & Media-alta y alta tecnología \\
\hline $\ln G D P P C_{j t}$ & $\begin{array}{l}0,212 \text { *** } \\
{[0,104]} \\
(2,05)\end{array}$ & $\begin{array}{l}0,234 * * * \\
{[0,099]} \\
(2,35)\end{array}$ & $\begin{array}{c}-0,128 \\
{[0,194]} \\
(-0,66)\end{array}$ & $\begin{array}{c}-0,081 \\
{[0,210]} \\
(-0,39)\end{array}$ \\
\hline $\ln P O P_{j t}$ & $\begin{array}{c}0,835^{* * * *} \\
{[0,028]} \\
(29,59)\end{array}$ & $\begin{array}{c}0,700 * * * \\
{[0,027]} \\
(25,83)\end{array}$ & $\begin{array}{l}1,087 * * * \\
{[0,052]} \\
(20,61)\end{array}$ & $\begin{array}{c}1,019 * * * \\
{[0,057]} \\
(17,80)\end{array}$ \\
\hline $\ln D I S T_{i j}$ & $\begin{array}{l}-0,296 * * * \\
{[0,054]} \\
(-5,42)\end{array}$ & $\begin{array}{l}-0,179 * * * \\
{[0,052]} \\
(-3,42)\end{array}$ & $\begin{array}{l}-0,587 * * * \\
{[0,102]} \\
(-5,75)\end{array}$ & $\begin{array}{l}-0,534 * * * \\
{[0,110]} \\
(-4,82)\end{array}$ \\
\hline $\operatorname{lnFDIOut}_{i t}$ & $\begin{array}{c}0,568 * * * \\
{[0,015]} \\
(36,81)\end{array}$ & $\begin{array}{c}0,441 * * * \\
{[0,014]} \\
(29,71)\end{array}$ & $\begin{array}{c}0,698 * * * \\
{[0,028]} \\
(24,18)\end{array}$ & $\begin{array}{c}0,883 * * * \\
{[0,031]} \\
(28,19)\end{array}$ \\
\hline $\ln R O Y A L T Y R C P T_{i t}$ & $\begin{array}{l}0,002 \\
{[0,015]} \\
(0,16)\end{array}$ & $\begin{array}{c}-0,025^{*} \\
{[0,014]} \\
(-1,68)\end{array}$ & $\begin{array}{l}0,049 * \\
{[0,029]} \\
(1,68)\end{array}$ & $\begin{array}{c}-0,114 \\
{[0,031]} \\
(-3,63)\end{array}$ \\
\hline Constante & $\begin{array}{l}-5,055^{* * * *} \\
{[0,939]} \\
(-5,38)\end{array}$ & $\begin{array}{l}-3,287 \text { *** } \\
{[0,902]} \\
(-3,64)\end{array}$ & $\begin{array}{l}-7,586^{* * * *} \\
{[1,755]} \\
(-4,32)\end{array}$ & $\begin{array}{l}-5,887 * * * \\
{[1,905]} \\
(-3,09)\end{array}$ \\
\hline$R^{2}$ ajustado & 0,919 & 0,889 & 0,833 & 0,843 \\
\hline
\end{tabular}

Fuente: elaborado por los autores.

Nota: las fuentes de las variables individuales están indicadas en el cuadro 3. Los errores estándar se indican entre corchetes. Las cifras entre paréntesis son los valores de t.

* Nivel de significancia del $10 \%$. *** Nivel de significancia del $1 \%$. 
CUADRO 6

Modelo gravitacional: análisis de la IED del exterior según el contenido tecnológico del comercioa

\begin{tabular}{|c|c|c|c|c|}
\hline & Todas las corrientes comerciales & Baja tecnología & Media-baja tecnología & Media-alta y alta tecnología \\
\hline $\ln G D P P C_{j t}$ & $\begin{array}{c}-0,215 \\
{[0,140]} \\
(-1,53)\end{array}$ & $\begin{array}{c}-0,115 \\
{[0,135]} \\
(-0,85)\end{array}$ & $\begin{array}{c}-0,540 * * \\
{[0,255]} \\
(-2,12)\end{array}$ & $\begin{array}{c}-0,705^{* *} \\
{[0,284]} \\
(-2,48)\end{array}$ \\
\hline $\ln G I N I_{j t}$ & $\begin{array}{c}-0,920 * \\
{[0,538]} \\
(-1,71)\end{array}$ & $\begin{array}{c}-0,814 \\
{[0,521]} \\
(-1,56)\end{array}$ & $\begin{array}{c}-0,481 \\
{[0,980]} \\
(-0,49)\end{array}$ & $\begin{array}{c}-1,187 \\
{[1,091]} \\
(-1,09)\end{array}$ \\
\hline $\ln P O P_{j t}$ & $\begin{array}{c}0,903 * * * \\
{[0,043]} \\
(20,69)\end{array}$ & $\begin{array}{c}0,759 * * * \\
{[0,042]} \\
(17,96)\end{array}$ & $\begin{array}{c}1,134 * * * \\
{[0,079]} \\
(14,27)\end{array}$ & $\begin{array}{c}1,111^{* * *} \\
{[0,088]} \\
(12,55)\end{array}$ \\
\hline $\ln D I S T_{i j}$ & $\begin{array}{l}-0,322 * * * \\
{[0,055]} \\
(-5,79)\end{array}$ & $\begin{array}{c}-0,199 * * * \\
{[0,053]} \\
(-3,70)\end{array}$ & $\begin{array}{c}-0,623 \text { *** } \\
{[0,101]} \\
(-6,15)\end{array}$ & $\begin{array}{c}-0,575 * * * \\
{[0,112]} \\
(-5,09)\end{array}$ \\
\hline $\operatorname{lnFDIIn}_{i t}$ & $\begin{array}{c}0,708^{* * * *} \\
{[0,020]} \\
(35,35)\end{array}$ & $\begin{array}{c}0,549 * * * \\
{[0,019]} \\
(28,31)\end{array}$ & $\begin{array}{c}0,869 * * * \\
{[0,036]} \\
(23,86)\end{array}$ & $\begin{array}{c}1,097 * * * \\
{[0,040]} \\
(27,03)\end{array}$ \\
\hline $\ln R O Y A L T Y R C P T_{i t}$ & $\begin{array}{l}0,081 * * * \\
{[0,015]} \\
(5,25)\end{array}$ & $\begin{array}{l}0,035^{* *} \\
{[0,014]} \\
(2,39)\end{array}$ & $\begin{array}{l}0,145^{* * * *} \\
{[0,028]} \\
(5,19)\end{array}$ & $\begin{array}{l}0,007 \\
{[0,031]} \\
(0,25)\end{array}$ \\
\hline Constante & $\begin{array}{c}-2,033 \\
{[2,544]} \\
(-0,80)\end{array}$ & $\begin{array}{l}-0,485 \\
{[2,462]} \\
(-0,20)\end{array}$ & $\begin{array}{c}-6,785 \\
{[4,627]} \\
(-1,47)\end{array}$ & $\begin{array}{c}-2,242 \\
{[5,155]} \\
(-0,43)\end{array}$ \\
\hline$R^{2}$ ajustado & 0,916 & 0,883 & 0,836 & 0,838 \\
\hline
\end{tabular}

Fuente: elaborado por los autores.

Nota: las fuentes de las variables individuales están indicadas en el cuadro 3. Los errores estándar se indican entre corchetes. Las cifras entre paréntesis son los valores de la prueba t.

a Sin considerar la desigualdad del ingreso y utilizando el coeficiente de Gini.

* Nivel de significancia del $10 \%$. ** Nivel de significancia del $5 \%$. *** Nivel de significancia del $1 \%$.

coinciden con el modelo en que se estimaba el papel de la IED del exterior en el comercio según contenido tecnológico (véase el cuadro 4) e indican que el PIB per cápita se mantiene negativo, la variable distribución del ingreso no tiene un efecto significativo. Cuando se analizan los intercambios comerciales sin tener en cuenta el contenido tecnológico, la desigualdad del ingreso no parece tener un efecto pronunciado dado que los coeficientes de Gini no son significativos ${ }^{9}$. Sin embargo, los resultados correspondientes a la IED en el exterior son totalmente diferentes (véase el cuadro 7): esta variable es significativa en todas las estimaciones,

\footnotetext{
${ }^{9}$ El coeficiente de Gini es significativo solo en la estimación correspondiente a "todas las corrientes comerciales". Dado que los resultados relacionados con los distintos niveles de contenido tecnológico no son significativos, no se tienen pruebas de que la desigualdad sea un factor importante a considerar en el modelo.
}

lo que demuestra que los países de origen de las EMN experimentan un efecto positivo. Entretanto, el PIB per cápita es positivo en la estimación de todas las corrientes comerciales y el comercio de baja tecnología, y el coeficiente de Gini es positivo y significativo en todas las estimaciones. Las restantes variables siguen los mismos patrones observados en estimaciones anteriores.

Estas dos últimas estimaciones, que incorporan el coeficiente de Gini, proporcionan alguna información interesante: el coeficiente de Gini compensa el efecto del PIB per cápita en el MERCOSUR, dado que se correlaciona positivamente con las corrientes comerciales en relación con la IED en el exterior. Los resultados de este estudio demuestran la significancia de la capacidad de internacionalización de los países — como países receptores y como países de origen de las EMN- en términos de comercio dentro del bloque. Este resultado es especialmente significativo en el caso de la IED del 
CUADRO 7 Modelo gravitacional: análisis de la IED en el exterior
según el contenido tecnológico del comercioa

\begin{tabular}{|c|c|c|c|c|}
\hline & Todas las corrientes comerciales & Baja tecnología & Media-baja tecnología & Media-alta y alta tecnología \\
\hline $\ln G D P P C_{j t}$ & $\begin{array}{l}0,471 \text { *** } \\
{[0,133]} \\
(3,53)\end{array}$ & $\begin{array}{l}0,417 * * * \\
{[0,130]} \\
(3,21)\end{array}$ & $\begin{array}{l}0,301 \\
{[0,251]} \\
(1,20)\end{array}$ & $\begin{array}{l}0,358 \\
{[0,273]} \\
(1,31)\end{array}$ \\
\hline $\ln G I N I_{j t}$ & $\begin{array}{l}1,505^{* * * *} \\
{[0,504]} \\
(2,98)\end{array}$ & $\begin{array}{l}1,062^{* *} \\
{[0,491]} \\
(2,16)\end{array}$ & $\begin{array}{l}2,504 * * * \\
{[0,949]} \\
(2,64)\end{array}$ & $\begin{array}{l}2,565 * * \\
{[1,032]} \\
(2,48)\end{array}$ \\
\hline $\ln P O P_{j t}$ & $\begin{array}{c}0,746^{* * * *} \\
{[0,040]} \\
(18,36)\end{array}$ & $\begin{array}{c}0,637 * * * \\
{[0,039]} \\
(16,13)\end{array}$ & $\begin{array}{c}0,939 * * * \\
{[0,076]} \\
(12,30)\end{array}$ & $\begin{array}{c}0,867 * * * \\
{[0,083]} \\
(10,44)\end{array}$ \\
\hline $\operatorname{lnDIST}_{i j}$ & $\begin{array}{l}-0,301 \text { *** } \\
{[0,053]} \\
(-5,65)\end{array}$ & $\begin{array}{c}-0,183 \\
{[0,051]} \\
(-3,53)\end{array}$ & $\begin{array}{c}-0,597 * * * \\
{[0,100]} \\
(-5,95)\end{array}$ & $\begin{array}{c}-0,543 * * * \\
{[0,109]} \\
(-4,98)\end{array}$ \\
\hline lnFDIOut $_{i t}$ & $\begin{array}{c}0,563 * * * \\
{[0,015]} \\
(37,03)\end{array}$ & $\begin{array}{c}0,437 * * * \\
{[0,014]} \\
(29,56)\end{array}$ & $\begin{array}{c}0,689 * * * \\
{[0,028]} \\
(24,11)\end{array}$ & $\begin{array}{c}0,874 * * * \\
{[0,031]} \\
(28,11)\end{array}$ \\
\hline $\ln R O Y A L T Y R C P T_{i t}$ & $\begin{array}{l}0,004 \\
{[0,015]} \\
(0,31)\end{array}$ & $\begin{array}{c}-0,023 \\
{[0,014]} \\
(-1,59)\end{array}$ & $\begin{array}{l}0,052 * \\
{[0,028]} \\
(1,84)\end{array}$ & $\begin{array}{l}-0,110^{* * * *} \\
{[0,031]} \\
(-3,56)\end{array}$ \\
\hline Constante & $\begin{array}{c}-11,741 \text { *** } \\
{[2,422]} \\
(-4,85)\end{array}$ & $\begin{array}{l}-8,007 * * * \\
{[2,357]} \\
(-3,40)\end{array}$ & $\begin{array}{c}-18,706 * * * \\
{[4,554]} \\
(-4,11)\end{array}$ & $\begin{array}{c}-17,278 * * * \\
{[4,953]} \\
(-3,49)\end{array}$ \\
\hline$R^{2}$ ajustado & 0,923 & 0,891 & 0,839 & 0,848 \\
\hline
\end{tabular}

Fuente: elaborado por los autores.

Nota: las fuentes de las variables individuales están indicadas en el cuadro 3. Los errores estándar se indican entre corchetes. Las cifras entre paréntesis son los valores de la prueba t.

a Sin tomar en cuenta la desigualdad del ingreso y utilizando el coeficiente de Gini.

* Nivel de significancia del $10 \%$. **Nivel de significancia del 5\%. ***Nivel de significancia del $1 \%$.

exterior y reveló la influencia positiva de las EMN en los patrones comerciales de estos países, lo que podría conducir, entre otras repercusiones, a una mayor capacidad de inversión en el exterior y al aumento de la competitividad de las empresas nacionales. Cuando se examina la IED en el exterior con respecto al coeficiente de Gini, dicha IED es significativa y tiene un coeficiente positivo que se incrementa en consonancia con el contenido tecnológico de las exportaciones y, asimismo, con los valores del coeficiente de Gini. Si bien la relación entre desigualdad en el reparto del ingreso y capacidades tecnológicas ofrece abundantes posibilidades de estudio que exceden el alcance de este trabajo, los presentes resultados proporcionan cierto respaldo para establecer una vinculación positiva entre contenido tecnológico y desigualdad. 


\section{V \\ Observaciones finales}

En este artículo se ha explorado la potencial capacidad de internacionalización de los países del MERCosur, considerando tanto los intercambios comerciales como los flujos de IED como motores de integración tecnológica en la región. Los resultados del análisis demuestran que las EMN tienen todavía una influencia bastante limitada en la integración tecnológica en la región, donde la transferencia de conocimiento en el interior del bloque ocurre más probablemente a través del comercio. Sobre la base del concepto de las capacidades de absorción y la importancia de los sistemas nacionales de innovación, nuestra primera conclusión es que la relación entre las corrientes internacionales y la meta común de aumentar la innovación y la competitividad regionales puede reforzarse, así como mediante el fortalecimiento del proceso de integración en el Mercosur. Una consecuencia indirecta de los presentes resultados es la posible influencia de las EMN dentro del bloque mediante la generación y mejora de las capacidades tecnológicas; no obstante, para este propósito habría que definir políticas comunes más precisas en materia de innovación, que reconocieran el papel de las empresas internacionales a fin de aprovechar sus operaciones en la región. En esta misma línea, el potencial de IED en el exterior de los países que integran el MERCOSUR debería explorarse y explotarse para acrecentar el aprendizaje de la región a partir de la presencia de sus socios en el exterior. De hecho, si se analiza el efecto en el comercio en los países de mayor tamaño (Argentina y Brasil) y los más pequeños (Paraguay y Uruguay), se destacan algunas consecuencias aplicables en materia de política, según mencionan Bekerman y Rikap (2010), como la importancia de armonizar las capacidades tecnológicas nacionales a través de iniciativas regionales.

Otras consecuencias se relacionan con la expansión de los modelos gravitacionales a fin de reflejar factores institucionales y de internacionalización. Las "variables gravitacionales" y el coeficiente de Gini fueron considerados como variables exógenas ${ }^{10}$, mientras que las mejoras de la capacidad de exportación - tanto en términos cuantitativos como cualitativos- dependen mayormente del volumen de IED. Los resultados del presente estudio revelan que las políticas destinadas a promover la IED en el exterior y atraer la IED del exterior pueden estimular las exportaciones de un país a sus socios del MERCosur, lo que señala la necesidad de formular políticas económicas y de tecnología más integradas a nivel del bloque. Por lo tanto, una línea de futura investigación de los autores de este trabajo tendrá como finalidad explorar la relación entre la desigualdad y el avance tecnológico, sobre la base de que el desarrollo económico debería mejorar la capacidad de absorción de los países. Para obtener una visión más acabada de los países en desarrollo deben investigarse los aspectos de su estructura institucional. Si nuevas pruebas empíricas vinieran a respaldar los resultados preliminares aquí obtenidos, sería crucial contar con políticas sólidas de redistribución a objeto de garantizar un proceso de integración internacional más sostenible para los países en proceso de convergencia.

\footnotetext{
${ }^{10}$ La distancia es exógena por definición. El PIB per cápita, el tamaño de la población y el coeficiente de Gini pueden considerarse relativamente exógenos en el enfoque adoptado en el presente documento, dado que este se centra en los aspectos institucionales y tecnológicos.
}

Alonso, J.A. y C. Garcimartín (2011), "Criterios y factores de calidad institucional: Un estudio empírico", Revista de Economía Aplicada, vol. 19, $\mathrm{N}^{\circ}$ 55, Zaragoza, Universidad de Zaragoza.

Álvarez, I. y J. Cantwell (2011), "International integration and mandates of innovative subsidiaries in Spain", International Journal of Institutions and Economies, vol. 3, $\mathrm{N}^{\mathrm{o}} 3$, Kuala Lumpur, University of Malaya.

Álvarez, I., R. Marín y A. Fonfría (2009), "The role of networking in the competitiveness of firms", Technological Forecasting and Social Change, vol. 76, $\mathrm{N}^{\circ} 3$, Amsterdam, Elsevier.
Anderson, J.E. (1979), "A theoretical foundation for the gravity equation”, American Economic Review, vol. 69, No 1, Nashville, Tennessee, American Economic Association.

Anderson, J.E. y E. Van Wincoop (2003), "Gravity with gravitas: a solution to the border puzzle", American Economic Review, vol. 93, $\mathrm{N}^{\circ}$ 1, Nashville, Tennessee, American Economic Association.

Archibugi, D. y A. Coco (2004), "A new indicator of technological capabilities for developed and developing countries (ArCo)", World Development, vol. 32, № 4, Amsterdam, Elsevier. 
Archibugi, D. y J. Michie (1995), "The globalisation of technology: A new taxonomy", Cambridge Journal of Economics, vol. 19, $\mathrm{N}^{\mathrm{o}}$ 1, Oxford, Oxford University Press.

Bekerman, M. y C. Rikap (2010), "Integración regional y diversificación de exportaciones en el MERCosur: El caso de Argentina y Brasil", Revista de la CEPAL, No 100 (LC/G.2442-P), Santiago de Chile.

Blomstrom, M. y A. Kokko (1997), "Regional integration and foreign direct investment", NBER Working Paper Series, № 6019, Cambridge, Massachusetts, National Bureau of Economic Research.

Bloningen, B.A. y otros (2007), "FDI in space: spatial autoregressive relationships in foreign direct investments", European Economic Review, vol. 51, № 5, Amsterdam, Elsevier.

Brenton, P., F. Di Mauro y M. Lücke (1999), "Economic integration and FDI: an empirical analysis of foreign investment in the EU and in Central and Eastern Europe”, Empirica, vol. 26, № 2, Springer.

Cantwell, J. (1989), Technological Innovation and Multinational Corporations, Oxford, Basil Blackwell.

Cantwell, J. y O. Janne (1999), “Technological globalisation and innovative centres: the role of corporate technological leadership and locational hierarchy", Research Policy, vol. 28, No 2-3, Amsterdam, Elsevier.

Cassiolato, J. y H. Lastres (1999), "Local, national and regional systems of innovation in the MERCOSUR", Río de Janeiro, Universidad Federal de Río de Janeiro.

Castellacci, F. y J.M. Natera (2011), "A new panel dataset for crosscountry analyses of national systems, growth and development (CANA)", Innovation and Development, por aparecer.

Chudnovsky, D. (2001), El boom de inversión extranjera directa en el MERCOSUR, Madrid, Siglo XXI.

Chudnovsky, D. y A. López (2007), "Inversión extranjera directa y desarrollo: La experiencia del MERCOSUR", Revista de la CEPAL, No 92 (LC/G.2339-P), Santiago de Chile.

Cuervo-Cazurra, A. (2007), "Sequence of value-added activities in the multinationalization of developing country firms", Journal of International Management, vol. 13, $\mathrm{N}^{\circ} 3$, Amsterdam, Elsevier.

Dahlman, C.J., B. Ross-Larson y L.E. Westphal (1987), "Managing technological development: lessons from the newly industrializing countries", World Development, vol. 15, No 6 , Amsterdam, Elsevier.

Dunning, J.H. (2006), "Towards a paradigm of development: implications for the determinants of international business activity", Transnational Corporations, vol. 15, № 1 .

(1981), International Production and the Multinational Enterprise, Londres, George Allen and Unwin.

(1977), "Trade, location of economic activity and MNE: a search for an eclectic approach", B.G. Ohlin, P.0. Hesselborn y P.M. Wijkman (eds.), The International Allocation of Economic Activity, London, Macmillan.

Dunning, J.H. y R. Narula (1996), Foreign Direct Investment and Governments: Catalysts for Economic Restructuring, London, Routledge.

Fagerberg, J. y M. Srholec (2009), "Knowledge, capabilities and the poverty trap: the complex interplay between technological, social and geographical factors", TIK Working Papers on Innovation Studies, N ${ }^{\circ} 20091218$, Oslo, Centre for Technology, Innovation and Culture, Universidad de Oslo [en línea] http://ideas.repec. org/s/tik/inowpp.html

(2008a), "National innovation systems, capabilities and economic development", Research Policy, vol. 37, № 9, Amsterdam, Elsevier.

(2008b), "Technology and development: unpacking the relationship(s)", TIK Working Papers on Innovation Studies, $\mathrm{N}^{\mathrm{o}} 20080623$, Oslo, Centre for Technology, Innovation and Culture, Universidad de Oslo.

Feenstra, R.C. (2002), "Border effects and the gravity equation: consistent methods for estimation", Scottish Journal of Political Economy, vol. 49, $\mathrm{N}^{\circ}$ 5, Wiley.

Feenstra, R.C., J.R. Markusen y A.K. Rose (2001), "Using the gravity equation to differentiate among alternative theories of trade",
The Canadian Journal of Economics, vol. 34, No 2, Quebec, Canadian Economics Association.

Frankel, J., E. Stein y S. Wei (1995), "Trading blocs and the Americas: the natural, unnatural, and the super-natural", Journal of Development Economics, vol. 47, № 1, Amsterdam, Elsevier.

Freeman, C. (2011), "Technology, inequality and economic growth", Innovation and Development, vol. 1, $\mathrm{N}^{\circ} 1$, Taylor and Francis.

Gerschenkron, A. (1962), Economic Backwardness in Historical Perspective, Cambridge, Massachusetts, Belknap Press.

Gil, R. y otros (2005), "The border effect in Spain", The World Economy, vol. 28, $\mathrm{N}^{\circ} 11$, Wiley.

Gonçalves, E., M.B. Lemos y J. De Negri (2008), “Condicionantes de la innovación tecnológica en Argentina y Brasil", Revista de la CEPAL, N 94 (LC/G.2357-P), Santiago de Chile.

Greenaway, D. y C. Milner (2002), "Regionalism and gravity", Scottish Journal of Political Economy, vol. 49, No 5, Wiley.

Hatzichronoglou, T. (1997), "Revision of the high-technology sector and product classification", OECD Science, Technology and Industry Working Papers, $\mathrm{N}^{\circ}$ 1997/2, París, OECD Publishing.

Helpman, E. (1984), "A simple theory of international trade with multinational corporations", The Journal of Political Economy, vol. 92, No 3, Chicago, The University of Chicago Press, junio.

Helpman, E. y P. Krugman (1985), Market Structure and Foreign Trade, Cambridge, MIT Press.

Helpman, E., M.J. Melitz e Y. Rubinstein (2008), "Estimating trade flows: trading partners and trading volumes", Quarterly Journal of Economics, vol. 123, $\mathrm{N}^{\mathrm{o}} 2$, Oxford University Press.

Katz, J. (1982), Technology Generation in Latin American Manufacturing Industries, Oxford, Pergamon Press.

Lall, S. (2000), "Technological change and industrialization in the Asian newly industrializing economies: achievements and challenges", Technology, Learning and Innovation Experiences of Newly Industrializing Economies, L. Kim y R.R. Nelson, Cambridge, Cambridge University Press.

- (1997), "Investment, technology and international competitiveness", The New Globalism and Developing Countries, J.H. Dunning y K.A. Hamdani, Tokio, United Nations University Press.

(1996), Learning from the Asian Tigers, Londres, Macmillan. (1992), "Technological capabilities and industrialization", World Development, vol. 20, No 2, Amsterdam, Elsevier.

López, A. y G. Lugones (1997), "El proceso de innovación tecnológica en América Latina en los años noventa. Criterios para la definición de indicadores", REDES, vol. 4, № 9, Buenos Aires, Universidad Nacional de Quilmes.

Lundvall, B.A. y B. Johnson (1994), “The learning economy”, Industry and Innovation, vol. 1, $\mathrm{N}^{\mathrm{o}}$ 2, Taylor and Francis.

Lundvall, B.A. y otros (2002), "National systems of production, innovation and competence building", Research Policy, vol. 31, $\mathrm{N}^{\circ}$ 2, Amsterdam, Elsevier.

Mortimore, M. y S. Vergara (2004), "Targeting winners: can foreign direct investment policy help developing countries industrialise?", The European Journal of Development Research, vol. 16, № 3, Taylor and Francis.

Narula, R. y J.H. Dunning (2000), "Industrial development, globalisation and multinational enterprises: new realities for developing countries", Oxford Development Studies, vol. 28, № 2, Taylor and Francis.

Narula, R. y K. Wakelin (1995), "Technological competitiveness, trade and foreign direct investment", Research Memorandum, $\mathrm{N}^{\mathrm{o}}$ 13, Maastricht, Maastricht Economic Research Institute on Innovation and Technology (MERIT).

Patel, P. y K. Pavitt (2000), "National System of innovation under strain: the internationalisation of corporate R\&D", Productivity, Innovation and Economic Performance, R. Barrell, G. Mason y O’Mahoney (eds.), Cambridge, Cambridge University Press.

RICYT (Red Iberoamericana de Indicadores de Ciencia y Tecnología) (2007), Manual de indicadores de internacionalización de la ciencia y la tecnología. Manual de Santiago, Buenos Aires. 
RICYT (2001), Standardisation of Indicators of Technological Innovation in Latin American and Caribbean Countries. Bogota Manual, Buenos Aires.

Rodrik, D. (1999), "The new global economy and developing countries: making openness work", Policy Essay, N²4, Washington, D.C., Consejo de Desarrollo de Ultramar.

Rosales, O. (2009), "La globalización y los nuevos escenarios del comercio internacional", Revista de la CEPAL, No 97 (LC/ G.2400-P), Santiago de Chile.

Rugman, A.M. y J.P. Doh (2008), Multinationals and Development, New Haven, Yale University Press.

Uchida, Y. y P. Cook (2005), "The transformation of competitive advantage in East Asia: an analysis of technological and trade specialization", World Development, vol. 33, № 5, Amsterdam, Elsevier, mayo.

UNCTAD (Conferencia de las Naciones Unidas sobre Comercio y Desarrollo) (2007), World Investment Report. Transnational Corporations, Extractive Industries and Development (UNCTAD/
WIR/2007), Nueva York, Naciones Unidas. Publicación de las Naciones Unidas, $\mathrm{N}^{\circ}$ de venta: E.07.II.D.9.

(2005), World Investment Report. Transnational Corporations and the Internationalization of $R \& D$ (UNCTAD/WIR/2005), Nueva York, Naciones Unidas. Publicación de las Naciones Unidas, $\mathrm{N}^{\mathrm{o}}$ de venta: E.05.II.D.10.

UsPTo (Oficina de Patentes y Marcas de los Estados Unidos) (2002), "Registered Patent Database", Washington, D.C. [en línea] www.uspto.gov.

Worth, T. (1997), "Regional trade agreements and foreign direct investment", Regional Trade Agreements and US Agriculture, Washington, D.C.

Xu, B. (2000), "Multinational enterprises, technology diffusion, and host country productivity growth", Journal of Development Economics, vol. 62, $\mathrm{N}^{\mathrm{o}}$ 2, Amsterdam, Elsevier.

Yoguel, G., J.A. Borello y A. Erbes (2009), "Argentina: Cómo estudiar y actuar sobre los sistemas locales de innovación", Revista de la CEPAL, $\mathrm{N}^{\circ} 99$ (LC/G.2418-P), Santiago de Chile. 